\title{
La poesía española de la democracia: procesos de canonización, selección y filtrado en el campo literario finisecular
}

\author{
Araceli Iravedra
}

(Universidad de Oviedo)

Si volvemos la mirada a la poesía española de los últimos decenios, advertimos que la llamada poesía de la experiencia, realista o figurativa, y en concreto algunos de sus nombres más relevantes han conocido un eco particularmente significativo fuera de nuestras fronteras, tal como demuestra, por ejemplo, la abundancia de trabajos académicos a ellos consagrados en distintas universidades americanas y europeas - no hay más que reparar en la bibliografía generada por la obra de Luis García Montero y Felipe Benítez Reyes, o en las aproximaciones a esta corriente lírica desde posturas tan dispares como las de Jonathan Mayhew (1999, 2002, 2009), Ana Eire (2003, 2005, 2009) o Raquel Medina (1998) - . Para que tal cosa ocurriera, antes fue necesario que la poesía de la experiencia se consolidase como corriente hegemónica en el campo poético español, ya que es principal - aunque no únicamente - la publicación sistemática (bien de poemarios individuales, bien de selecciones que los incluyen) en potentes editoriales con capacidad de distribución en el exterior lo que les ha procurado una inmediata proyección internacional. Partiendo de esta premisa, me propongo revisar el conjunto de factores que considero han intervenido en el proceso de canonización de la poesía de la experiencia, y ello en estrecha conexión con las pugnas por la centralidad que, desde otras latitudes líricas, se han dejado sentir en la escena literaria nacional desde que el figurativismo conquistase la supremacía estética.

Una ojeada retrospectiva nos permite hoy situar el proceso de afirmación de la poesía de la experiencia como paradigma dominante en el segundo lustro de los años ochenta, en un momento en que la convivencia equilibrada de estéticas a que asistimos en los primeros años de la década se reduce y polariza, como consecuencia del declive que acusan algunas de las que se habían mostrado más vigorosas en su primera mitad. Para entonces, sucediendo a la madrugadora apuesta de García Martín por una 
línea “experiencial” y reflexiva en Las voces y los ecos, selección de 1980 que atendía al segundo tramo de la hornada sesentayochista, las más influyentes antologías fundacionales de la nueva generación ya privilegiaban más o menos resueltamente en sus nóminas a los autores de la vertiente figurativa; solo que, mientras Luis Antonio de Villena empleaba en Postnovísimos (1986) el rótulo de "tradición clásica”, García Martín se refería en La generación de los ochenta (1988) a los "realistas" y "elegíacos" como las "opciones estéticas que se consideran particularmente valiosas" (1988: 48). A su vez, los primeros intentos de sistematización que, desde algunas publicaciones periódicas, acudían hacia finales de la década a matizar o a completar los mapas generacionales propuestos en las antologías ya alertaban de algunas llamativas operaciones de promoción de la corriente. Así, Amparo Amorós (1989: 63-67) se refería al lanzamiento orquestado por los autores de la otra sentimentalidad granadina, que habían publicado su manifiesto fundacional en las páginas del diario El País, como un hábil montaje propagandístico cuyos resultados "no los mejora ni Castellet"; y avisaba, asimismo, de la "voluntad decidida y manifiesta" de imponer la poesía de la experiencia desde algunas editoriales andaluzas como Calle del Aire y, posteriormente, Renacimiento, y desde revistas como Fin de Siglo, Contemporáneos o, de nuevo, Renacimiento. Con todo, no será sino en un trabajo casi coetáneo, publicado bajo el rótulo de "La poesía de la experiencia y su tradición”, donde Enrique Molina Campos rompa con el tópico de la pluralidad y la codominancia de estéticas que, pese a todo, aún prevalecía para referirse a la mencionada en el título como la más significativa, al menos cuantitativamente (1988: 41-47). Y, en efecto, si el término designador aún había de tardar en generalizarse, hoy no cabe duda de que, a esas alturas de la década, la tendencia realista se había hecho con un lugar de privilegio en el campo de la nueva poesía.

No en vano, cuando Luis Antonio de Villena renueve su radiografía del presente poético en una segunda antología, Fin de siglo, publicada en 1992, suscribirá en su ensayo introductorio el indiscutible predominio de la "poesía de sesgo clásico", término que subtitulaba esta muestra "de vocación declaradamente parcial” - según el antólogo confesaría después - y que no pretendía sino "dar historia y amplitud a lo que suele llamarse poesía de la experiencia" (Villena 1997: 15). En el mismo año 1992, otros críticos confirman la hegemonía del paradigma realista. José Luis García Martín, que bautiza la corriente con el nombre de "poesía figurativa” en un libro así titulado, considera que los que denomina poetas figurativos constituyen el grupo dominante y más influyente en los últimos quince años de la poesía española (García Martín 1992b: 208-227). Pero no solo eso: en un panorama introductorio para el volumen 9 de la Historia y Crítica de la Literatura Española, acude a unas palabras de Gabriel Ferrater, sintomáticamente las mis- 
mas que en el trabajo citado había empleado para resumir el figurativismo, ${ }^{1}$ a modo de síntesis del rumbo que tomaban Los nuevos nombres (1992) poéticos. La lectura parcial o, cuando menos, generalizadora que estaba operando en las páginas institucionalizadoras de este manual es un índice exacto de que el modelo realista se había instaurado como noción dominante, había establecido una norma diferenciada que conformaba el horizonte de la nueva creación e identificaba la escritura de la generación última. Tanto es así que cuando Miguel García-Posada publique en una colección de la editorial Crítica, de marcada pretensión académica, el volumen consagrado a La nueva poesía (1975-1992), tanto los rasgos consignados en el prólogo como singularizadores de esta - o de su vertiente más “avanzada" - como la propia nómina de autores se saldan a favor de la poesía de la experiencia. Ello por no hablar de las propuestas antológicas indisimuladamente programáticas que acompañan a esta en la década de los noventa, como Selección nacional (1995), de José Luis García Martín, o Los poetas tranquilos (1996), de Germán Yanke, para citar solo las más militantes.

En la consolidación de esta nueva poesía hegemónica colaboran, por lo tanto, y no cabe negarlo, el respaldo editorial y crítico; también, seguramente, la convergencia de varias generaciones sucesivas, incluida la del 50 aún en activo, aunque, de modo más resuelto, la segunda promoción de la hornada del 68; sin soslayar, por qué hacerlo, la indiscutible calidad poética de no pocos de sus cultivadores. Como ha recordado Juan José Lanz (2007: 200), la obtención de premios importantes y el reconocimiento de algunos libros de los autores de mayor edad inscritos en esta clave estética - La caja de plata (1985), de Luis Alberto de Cuenca, Curso superior de ignorancia (1987), de Miguel d'Ors, Las tardes (1988), de Francisco Bejarano o Volverlo a intentar (1989), de Javier Salvago, son galardonados con el Premio de la Crítica - ratifica y apuntala el canon emergente. Habrá que contar, asimismo, con el mencionado declive de tendencias tan pujantes en los primeros ochenta como el neosurrealismo y la poética del silencio. Pero aún hay otros factores que conviene analizar, alguno indesligable del primero de los citados, y que aconsejan dedicar alguna atención a los debates poéticos que se dan en estos años.

Tan pronto como la poesía de la experiencia se consolida como tendencia dominante, comienza a fraguarse una reacción proveniente de diversos autores y núcleos que habían quedado marginados en el mapa poético. Estéticamente hablando, la respuesta se funda en un amplio concepto de experimentación y de indagación expresiva que, ya en los años noventa, encuentra su primera materialización antológica coherente en La prueba del nueve (1994). Su editor, Antonio Ortega, recogía allí a un conjunto

1 “'Claros, sensatos, lúcidos y apasionados', quieren estos poetas que su verso tenga, por lo menos, las características de la buena prosa” (García Martín 1992a: 124; 1992b: 227). 
de poetas, en buena parte coincidentes con el grupo vallisoletano de $E l$ signo del gorrión, que se entregaban a una exploración crítica de la realidad desde lenguajes no figurativos basados en la fractura del texto. Y, sin que el prólogo a la selección mostrase una abierta beligerancia contra los autores realistas, en la presentación de una poesía crítica que no otorga concesiones a la "versión socialmente concordada" ni "literariamente armonizada" de la realidad, escrita en un lenguaje "lejano de cualquier forma de consuelo o seducción" (Ortega 1994: 9-36), latía una imputación directamente dirigida - como bien vio José-Carlos Mainer - "al corazón conformista y trivial de la 'poesía de la experiencia”" (Mainer 1998: 33). En efecto, así venía a confirmarlo la censura mucho más rotunda formulada en ese mismo año por uno de los autores incluidos en la selección: bajo una elocuente pregunta retórica - “¿Crítica militante?”-, Juan Carlos Suñén publicaba un artículo manifiestamente combativo que denunciaba la perniciosa parcialidad de criterio de uno de los críticos más influyentes, José Luis García Martín, cuya indisimulada simpatía y favor continuado a la poética figurativa lo convertía en corresponsable de la hegemonía de la tendencia y el consiguiente "empobrecimiento general de la cultura". Suñén elaboraba un análisis bipolar del panorama lírico, que le llevaba a teorizar sobre las "dos familias poéticas" que se habían venido fraguando en los últimos años, enfrentadas en lo formal, pero también en lo ideológico, y que respondían al fin a las "viejas posiciones entre comunicación y conocimiento". Y mientras tildaba la primera (que identificaba, implícitamente, con la poesía de la experiencia) de retórica e ideológicamente conservadora, ante todo complaciente con un lector del que solicitaba una adhesión sin condiciones y que evitaba, en consecuencia, cualquier riesgo de interferencia comunicativa o de ruptura de expectativas ético-estéticas susceptible de provocar su irritación o su rechazo, atribuía a la segunda una vocación "más arriesgada", en tanto buscaba un texto no solicitado, "concebido lejos de toda demanda", y a la que calificaba por tal causa de perturbacionista, reservando para la anterior el título de gratificacionista. Lejos de la audacia estética de aquella, el peaje de esta se infería fácilmente: la renuncia a la originalidad artística, a la voz propia y a la investigación lingüística en nombre de un estrecho catálogo de convenciones previamente consensuadas con el lector (Suñén 1994: 13-27).

En realidad, las razones de Juan Carlos Suñén no hacían sino explicitar lo que se leía entre líneas en el discurso prologal de Antonio Ortega y concordaban con la tendencia ilustrada en La prueba del nueve: una antología programática concebida como plataforma de una corriente de sesgo metafísico que acudía a compensar los numerosos panoramas generacionales orientados hacia la vertiente figurativa. Así que en la iniciativa había que ver una tentativa editorial de adquisición de capital cultural y simbólico; pero también la reivindicación de una alternativa estética que ha- 
bía quedado desplazada a los márgenes del canon. Sin embargo, el debate siempre saludable pierde nobleza y fuste cuando la argumentación estética se adelgaza o incluso se ausenta para mostrar al desnudo la batalla por las hegemonías. Y, sin duda, esta conoce su episodio más inequívoco en la acometida protagonizada por los autodenominados "poetas de la diferencia”, congregados alrededor del suplemento literario del diario Córdoba y capitaneados por su director Antonio Rodríguez Jiménez. Sin constituir un grupo estéticamente trabado, estos autores definían su personalidad poética en la estricta oposición a la dominante experiencial; sin embargo, las difusas caracterizaciones ensayadas por los propios teóricos de la diferencia (cf. Peña 1995; Rodríguez Jiménez 1996) no acababan de acotar una personalidad en verdad diferenciada, y tampoco sus antologías - El bilo de la fábula (Garrido Moraga 1995) o Elogio de la diferencia. Antología consultada de poetas no clónicos (Rodríguez Jiménez 1997) - permitían apreciar una especificidad estética que otorgase verdadera coherencia y unidad al conjunto: antes bien, según allí se declaraba, se trataba de "hacer justicia” a una serie heterogénea de poetas que había permanecido al margen de los circuitos "oficiales"; por lo que no es aventurado interpretar en todo ello una maniobra de reparación o de promoción mediática.

A la luz de episodios como este, una parte de la crítica ha creído ver en el fundamento de los ataques a los poetas realistas presupuestos políticos - o de "pequeña política literaria" - antes que propiamente estéticos (García Martín 1996: 32-33; Villena 1997: 9-10). Tanto más cuanto que el eje de la polémica se radicaba - y lo hizo muy a menudo- sobre el asunto de la repercusión alcanzada por las producciones de la experiencia. De hecho, este es el argumento central sobre el que pivota uno de los primeros enfrentamientos entre experienciales y diferentes, desplegado en un conjunto de artículos publicados en 1995 en la revista Claves de Razón Práctica. El texto de Felipe Benítez Reyes que abre el fuego, decidido a hacerse eco de los embates casi siempre desoídos de los detractores, se enfrenta a una de las acusaciones más reiteradas a las filas del realismo - la de controlar los mecanismos de institucionalización literaria y ejercer el dominio de los órganos de poder, cuyos favores garantizarían su éxito-y niega la presunta marginalidad, independencia y heterodoxia de quienes, mientras proclaman esta posición heroica, no dejan, de hecho, de hacerse oír en suplementos literarios y revistas, de recibir tratamiento de clásicos en publicaciones académicas y de beneficiarse de toda clase de patrocinios privados y públicos: "cajas de ahorro, diputaciones provinciales y ayuntamientos, esas instituciones clandestinas y subversivas que - ironiza el poeta - tanto fomentan el malditismo y la destrucción de la oficialidad". La conclusión, en consecuencia, del poeta de Rota es que el belicoso pataleo de los diferentes no es sino el fruto de una insaciable vanidad pisoteada por la falta de reconocimiento (Benítez Reyes 1995: 52-55). 
En sintonía con este discurso, José Luis García Martín se esforzaba por las mismas fechas en desmontar los argumentos de quienes se decían amenazados por el poder omnímodo de una "línea hegemónica”, aupada en una interacción de intereses político-literarios, que monopolizaba premios y ayudas oficiales, era apoyada por la crítica más influyente y servía de soporte ideológico al partido del Gobierno: afirmaciones todas que - según trataba de demostrar el crítico - quedaban desmentidas por la rotundidad de los hechos. En síntesis, aducía García Martín que los premios importantes iban a parar indistintamente a poetas experienciales y antiexperienciales (y, en efecto, el Loewe lo obtenían Luis García Montero y Felipe Benítez Reyes, pero también Jaime Siles y Álvaro Valverde; el Premio Nacional de Literatura lo compartían Francisco Brines y José Ángel Valente; y el Premio de la Crítica, Andrés Sánchez Robayna y Andrés Trapiello); unos y otros, asimismo, se repartían protagonismo y voz en las columnas de los suplementos más difundidos (y, así, las reseñas de Miguel García-Posada, valedor de la corriente figurativa en el diario $E l$ País, eran contrarrestadas por las de Juan Carlos Suñén, Miguel Casado o Antonio Ortega en la misma publicación); y algunas de las revistas más prestigiosas - Ínsula, El Urogallo- dedicaban amplios espacios e incluso privilegiaban a los no experienciales. Por último, el argumento de la proximidad al partido del Gobierno (el PSOE por entonces) se vería terminantemente refutado por algunos de los representantes más conspicuos de la tendencia, y desde posturas políticas tan divergentes como la izquierda antigubernamental - García Martín señalaba a Luis García Montero, activo militante de Izquierda Unida - o la derecha más conservadora - Miguel d'Ors, en quien se ha llegado a ver un propagandista del Opus Dei (Provencio 1994: 35), como caso sin duda más extremo-. Por todo ello, en suma, la escasa popularidad de los no figurativos no habría de relacionarse con ninguna suerte de confabulación marginadora, sino, más probablemente, o con la ausencia de calidad o con el fracaso en la conexión con el público lector (García Martín 1995: 10-12).

Conviene ir por partes. La ausencia de calidad nunca es un motivo desdeñable y justifica, desde luego, numerosas marginaciones y fracasos individuales; sin embargo, no resulta verosímil sostener que unos determinados supuestos estéticos (en este caso, aquellos que se alejan de la línea realista) conciten un generalizado alineamiento de la mediocridad. No hay que decir que para que una tendencia obtenga el éxito resulta estrictamente necesario que la asistan o cultiven poetas notables; estrictamente necesario, pero no necesariamente suficiente. Hay que pensar, así pues, en otros factores que inciden en el arrumbamiento de las corrientes no figurativas (metafísicos, neopuristas, neovanguardistas o experimentales) en beneficio de la tendencia realista. Y me inclino a sostener que la clave de bóveda de su muy desigual fortuna se halla en la distinta posición de 
unas y de otras ante la instancia del lector. La poesía que nace con los años ochenta y que fue bautizada como "poesía de la experiencia” expresó reiteradamente su inquietud ante el acusado divorcio que, a tenor del escaso número de consumidores, el género iba mostrando respecto del mundo contemporáneo; y, con el fin de restaurar el perdido pacto de lectura, reveló una verdadera voluntad de soldar la fractura instaurada entre poesía y sociedad y de trabajar en la búsqueda de una respuesta a aquello que esta última parecía solicitar. Dio, así, en propagar una noción de la escritura como artefacto necesario, haciendo residir su utilidad en la recreación estética de argumentos comunes que pudieran interesar a los lectores, en la concepción del sujeto que habla en el poema como una persona "normal", susceptible de representar la capacidad de sentir de cualquier ciudadano, y en el uso poético de la lengua social; en definitiva, en la fabricación de un espacio dialógico capaz de servir de escenario intermedio entre la vida del autor y la del lector (cf. García Montero 1993). No otra cosa pretende nombrar lo que se denominó “pacto realista” (Juaristi 1999), un planteamiento estético que unos llamaron cómplice y los otros complaciente, y que Laura Scarano definió atinadamente como "una textualización consensuada de lo real, apoyada en un código ideológico y retórico común a emisor y receptor, que asegura la legibilidad del mensaje por las referencias a un sistema de valores institucionalizado" (2004: 210). Las opciones estéticas no figurativas, instaladas en la tradición de la ruptura que ya había alimentado a la poesía novísima, apostaban, en cambio, por la investigación de una escritura experimental y proclive al fragmentarismo discursivo, orientada a vulnerar el lenguaje de uso y, por lo tanto, alejada de los pactos lingüísticos hacia una expresión intencionalmente hermética que, lejos de estar encaminada a la práctica de un discurso socializado, más bien se establecía como su negación radical: todo ello en virtud de un cuestionamiento de la funcionalidad comunicativa del lenguaje, así como de su capacidad de representación de otra realidad distinta de la socialmente convenida, que implicaba la obturación del diálogo entre emisor y receptor. Y la dinámica cíclica que rige los procesos culturales no jugó a favor de esta orientación; antes bien: tras el cansancio provocado por el experimentalismo radical, la exhibición culturalista y la oclusión comunicativa de los poetas novísimos, fue el esfuerzo por convertir el poema, antes que nada, en lugar de encuentro y diálogo entre poeta y lector el que se granjeó las inmediatas simpatías - cito ahora a García Martín (1995: 27) - de "esa minoría [...] que en cada momento determina el gusto estético”. Si contamos con que hablar de minorías en poesía vale tanto como hacerlo de un público endogámico - poetas, críticos de poesía o, mejor aún, poetas-críticos de poesía-, pienso que no ha de atribuirse sino a tales simpatías el trato de favor indiscutible que, desde mediados de los ochenta, vinieron dispensando al figurativismo los distintos instrumentos 
de institucionalización literaria: sobre todo, esas herramientas decisivas de canonización que son los repertorios antológicos.

Pero tal vez sea el momento de pararse a subrayar que, como ya podrá ir concluyéndose, en la oposición a la corriente de la experiencia de ningún modo ha de verse, sin más, un nervioso pataleo de poetas fracasados en busca de notoriedad, según la interesada conclusión extendida en algunos circuitos. Por descontado que existía la lucha por la centralidad - “en literatura todo es contienda”, tal y como ya sentenció Mainer (1999: 11)$\mathrm{y}$, de hecho, en no pocas ocasiones condujo a desmesurar o a equivocar los argumentos: no puede explicarse de otro modo, sino por combatir un liderazgo en el que a menudo se apreciaron ribetes de prepotencia, descalificaciones como las que han tildado la poesía de los seres normales de Luis García Montero como el primer peldaño "hacia un modelo de cultura neofascista" (Colectivo 1997: 116). Precisamente como una ingeniosa réplica global a esta suerte de embestidas y desvíos argumentativos irrumpía en los años noventa en la escena editorial El Sindicato del Crimen (1994), divertida broma antológica promovida por Felipe Benítez Reyes. En ella el autor, que bajo el pseudónimo de Eligio Rabanera pasaba por ser un teórico de la "diferencia”, reunía en un discurso disparatado e hiperbólico todos los cargos que se le habían venido imputando a la tendencia figurativa, y, por vía de reducción al absurdo, deslegitimaba con habilidad los argumentos de los detractores: el poeta dominante - argüía, por ejemplo- tiende a "acaparar premios importantes, antologías, historias de la literatura, suplementos literarios, revistas, congresos, editoriales, asociaciones de vecinos, clubs de caza y pesca, cursos de verano, endecasílabos" (Rabanera 1994: 11). Si Benítez Reyes buscaba, en fin, desde el mismo título de la muestra, neutralizar paródicamente los excesos en que incurrían las censuras de sus oponentes, no debemos ceder a la innegable eficacia de su inteligencia satírica. Pues en el pleito enconado entre integrados y marginales no actuaba solo, como quería el gaditano, la persecución de "la fama del infame" (1996: 79); se enfrentaban, asimismo, posiciones ideológicas y, de camino, actitudes ante el lenguaje que incidían de manera decisiva en la fabricación retórica del poema. Los argumentos más elaborados traslucían un sincero rechazo de las posturas débiles congruentes con el paradigma acrítico y trivializador de la posmodernidad, tanto como una plausible prevención ante el no siempre bien digerido concepto de normalidad, a menudo responsable de la perpetuación de una poesía tan seductora como simplista e intransigente con cualquier forma de disidencia estética. Una poesía contra la que se propuso - incluso desde dentro de la poesía de la experiencia - una escritura "inquietante" e "incómoda” y "una iluminación no siempre halagadora” con su lector (Piquero 1995: 138).

Y venimos, así, a parar de nuevo a las implicaciones posibles del "pacto realista”, esto es, de esa búsqueda de los vínculos y las formas de com- 
plicidad que el poema de la experiencia deja a cuenta de un sujeto emisor emplazado en el centro del cuerpo social. En un sentido, y pese a la pirueta desautorizadora de Felipe Benítez Reyes, no le faltaba toda la razón a Eligio Rabanera cuando sugería, entre otras cosas, que el éxito de la tendencia realista obedecía a su aquiescencia con el orden estatuido y a su capacidad para complacer - en su facilidad ramplona - al público lector. La aseveración, desde luego, merece matizarse: hay que rebajar su rotundidad, ajustar el recorrido de los argumentos y aliviarlos de su carga peyorativa; pero no es un desatino aventurar que una parte de las claves de la popularidad de la experiencia reside en su feliz ensambladura con el nuevo Estado cultural que surge con la democracia y con el nuevo lector fraguado a su arrimo, hijo de una sociedad más placentera y confortable. Precisamente Álvaro Salvador, uno de los poetas más autocríticos con los excesos de la experiencia $-y$, digámoslo todo, no de los mejor acogidos por el canon -, lanzaba en 1996 para denominar a esta corriente la etiqueta un tanto envenenada de "poesía de la socialdemocracia”. Y aunque negaba cualquier matiz peyorativo - y atenuaba: al menos, "poesía en la socialdemocracia" - , asoma en sus razones la denuncia de los resabios totalitarios de una política cultural que auspiciaba una literatura de la “normalización”, paradójicamente excluyente y digerible por una nueva estructura social:

Poesía en la socialdemocracia también, porque la recepción de esos "discursos poéticos normalizados", que se han abierto paso en los últimos quince años hasta convertirse en "norma" hegemónica, tiene mucho que ver con la aparición de ciertos grupos sociales emergentes, nuevas clases medias consolidadas al amparo de la política socialista, que han demandado la producción y el consumo de una cultura, así mismo, "media”, digerible, y que analizamos con más detenimiento en otro lugar. (Salvador 2003: 228)

De la implantación y demanda de esta cultura "media” y "digerible", apta para un lector conservador que busca formas de fruición ya familiares y un lenguaje sin sorpresas, resultaron las posturas intransigentes con el hermetismo vanguardista, tendentes a la "neutralización de toda disidencia" en nombre de un concepto de lo popular que, restringido a la inmediatez acrítica de "lo fácil", se confundía peligrosamente con lo populista. Y resultó la identificación demasiado frecuente - con palabras de Jaume Pont - entre "conflicto" y "confusión”, lo cual fue interpretado a menudo como una "llamada al orden institucional”, además de como un corolario de la renuncia posmoderna al conflicto ideológico y la cultura crítica en favor de un pragmatismo trivializador y de la sociedad del espectáculo. En el fondo, y por ello, la sospecha última de los impugnadores de la experiencia recaía sobre el envanecimiento de una "estética blanda”, 
deudora de la constitución de un corpus cultural autocomplaciente y de la regularización de la cultura como objeto de consumo, que se plegaba a los valores de una nueva "sociedad de lo fútil" (Pont 2005: 259-268). JoséCarlos Mainer, que también creyó ver bajo el agrio debate entre realistas y los otros una cuestión política concerniente al papel de la literatura en la vida social y, en última instancia, una desaprobación de la connivencia de los primeros con el Estado cultural afianzado durante el régimen socialista, fue seguramente quien se aventuró a llevar más lejos esta clase de argumento, arriesgando la siguiente reflexión provocadora:

¿Podrá ser casual, dirán algunos, que en 1983 surja "la otra sentimentalidad”? ¿No son los "poetas de la experiencia" la encarnación viva de la petulancia un poco hortera de los "sociatas" que acababan de llegar a las poltronas? ¿No son sus almibarados poemas y sus bellas revistas oficiales de los años ochenta una suerte de P.E.R. (Plan de Empleo Rural) para poetas andaluces en paro? (Mainer 1999: 37)

Ahí queda la provocación, y no la tomemos por completo a broma. Sin embargo, y aun así, no hay razón para que nos inquietemos en exceso. La poesía de la experiencia tuvo la fortuna de saber responder a las demandas culturales de su tiempo; pero, después de todo, tengo para mí que el éxito de la corriente (que - sobra decirlo - no consagra a cuantos eligen abrazarla) nunca habría sido tal sin la calidad indiscutible de algunos de sus cultivadores, poetas con el temperamento suficiente para crear escuela de imitadores y alzarse como figuras de referencia de más de una generación. Solo después colaboró la simpatía del lector contemporáneo y la acogida propicia de medios universitarios, secciones críticas de periódicos y revistas, congresos y seminarios de verano... Por último, ya se sabe que "el canon es una permanente actualización del pasado" (Mainer 1998: 274) y se encuentra, así pues, en perpetua mutación. Y contra los mecanismos que intervienen en la conformación anecdótica de una época literaria - llámense revistas, antologías, manifiestos, fotografías de grupo o encuentros emblemáticos-, contra las instancias, en fin, que controlan la literatura que se escribe en cada época, está siempre la historia:

El presente - ha escrito otra vez Benítez Reyes con su pizca de agudeza y su condimento de cinismo - puede ser una afanosa configuración colectiva, pero el futuro es siempre el futuro, y ya se sabe que los futuros literarios son siempre mucho más listos que los presentes literarios, esos trampantojos que pueden depender de unos periodistas en prácticas, de los directores de unos cursos de verano o de la salud estomacal de los críticos de los periódicos de circulación nacional. (1995: 54) 
La historia, en cambio, no se chupa el dedo y - esto es tan tópico como cierto - no hay mejor aliado de la buena literatura que la fértil labor justiciera del tiempo.

\section{BiBLIOGRAFÍA}

Amorós, Amparo (1989): “¡Los novísimos y cierra España! Reflexión crítica sobre algunos fenómenos estéticos que configuran la poesía de los años ochenta”. En: Ínsula, 512-513, pp. 63-67.

Benítez Reyes, Felipe (1996): “Lo que sostiene Rodríguez”. Claves de Razón Práctica, 61, pp. 79-80.

- (1995): "La nueva poesía española. Un problema de salud pública”. En: Claves de Razón Práctica, 58, pp. 52-55.

Colectivo Alicia Bajo Cero (1997): Poesía y poder. Valencia: Ediciones Bajo Cero.

EIre, Ana (2009): "El sentir del tiempo en la poesía de Eloy Sánchez Rosillo”. En: Hispania, XCII, 2, pp. 223-233.

- (2005): Conversaciones con poetas españoles contemporáneos. Sevilla: Renacimiento.

- (2003): "La poesía de la experiencia en la postmodernidad: un acercamiento a la nueva poesía española a través de la obra de Luis García Montero, Miguel d'Ors y Andrés Trapiello". En: Hispania, LXXXVI, 2, pp. 220-230.

García Martín, José Luis (ed.) (1996): Treinta años de poesía española, Sevilla/ Granada: Renacimiento/Comares.

— (ed.) (1995): Selección nacional. Última poesía española. Gijón: Llibros del Pexe.

- (1992a): “La poesía”. En: Rico, Francisco/Villanueva, Darío (eds.): Historia y crítica de la literatura española. 9. Los nuevos nombres: 1975-1990. Barcelona: Crítica, pp. 94-124.

- (1992b): La poesía figurativa. Crónica parcial de quince años de poesía española. Sevilla: Renacimiento.

— (ed.) (1988): La generación de los ochenta. Valencia: Mestral.

- (ed.) (1980): Las voces y los ecos. Madrid/Gijón: Júcar.

García Montero, Luis (1993): “¿Por qué no sirve para nada la poesía? (Observaciones en defensa de una poesía para los seres normales)”. En: García Montero, Luis/Muñoz Molina, Antonio: ¿Por qué no es útil la literatura? Madrid: Hiperión, pp. 9-41.

García-Posada, Miguel (1996): La nueva poesía (1975-1992). Barcelona: Crítica. Garrido Moraga, Antonio (ed.) (1995). El hilo de la fábula. Una antología de poesía española actual. Granada: Antonio Ubago.

Juaristi, Jon (1999): “El pacto realista”. En: Sermo humilis (Poesía y poéticas). Granada: Diputación Provincial (Maillot Amarillo), pp. 103-107. 
Lanz, Juan José (2007): La poesía durante la Transición y la generación de la democracia. Madrid: Devenir.

Mainer, José-Carlos (1999): “Para otra antología”. En: García Sánchez, Jesús (ed.): El último tercio del siglo (1968-1998). Antología consultada de la poesía española. Madrid: Visor, pp. 9-40.

- (1998): "Sobre el canon de la literatura española del siglo xx”. En: Sullà, Enric (ed.): El canon literario. Madrid: Arco/Libros, pp. 271-299.

Mayhew, Jonathan (2009): The Twilight of the Avant-Garde: Spanish Poetry 1980-2000. Liverpool: Liverpool University Press.

- (2002): "Poetry, Politics and Power". En: Journal of Spanish Cultural Studies, 3, 2, pp. 237-247.

- (1999): "The Avant-Garde and its Discontents: Aesthetic Conservatism in Recent Spanish Poetry”. En: Hispanic Review, 67, pp. 347-363.

Medina, Raquel (1998): “Poesía española 'fin de siglo': La experiencia y otros fantasmas poéticos”. En: Revista de Estudios Hispánicos, XXXII, 3, pp. 597612.

Molina Campos, Enrique (1988): "La poesía de la experiencia y su tradición”. En: Hora de Poesía, 59-60, pp. 41-47.

Ortega, Antonio (ed.) (1994): La prueba del nueve (Antología poética). Madrid: Cátedra.

Peña, Pedro J. de la (1995): "De la igualdad a la diferencia”. En: Cuadernos del Sur (suplemento literario del diario Córdoba), 2 de febrero, pp. 34-35.

Piquero, José Luis (1995): “Luces de situación”. En: García Martín, José Luis (ed.): Selección nacional. Última poesía española. Gijón: Llibros del Pexe, pp. 137-138.

PonT, Jaume (2005): “La poesía hispánica de vanguardia y la formación del canon”. En: Sánchez Robayna, Andrés/Doce, Jordi (eds.): Poesía hispánica contemporánea. Ensayos y poemas. Barcelona: Galaxia Gutenberg/Círculo de Lectores, pp. 245-273.

Provencio, Pedro (1994): "Las últimas tendencias de la lírica española". En: Cuadernos Hispanoamericanos, 531, pp. 31-54.

Rabanera, Eligio [pseud. Benítez Reyes, Felipe] (ed.) (1994): El Sindicato del Crimen. Antología de la poética dominante. Granada/Sevilla: Comares/Renacimiento.

Rodríguez Jiménez, Antonio (ed.) (1997): Elogio de la diferencia. Antología consultada de poetas no clónicos. Córdoba: Publicaciones Obra Social y Cultural Cajasur.

- (1996): “Diferencia 'versus' experiencia. La poesía heterodoxa frente a la tendencia oficial”. En: Claves de Razón Práctica, 60, pp. 77-78.

SAlvador, Álvaro (2003): "La experiencia de la poesía”. En: Letra pequeña. Granada: Los Cuadernos del Vigía, pp. 227-236.

Scarano, Laura (2004): Luis García Montero: la escritura como interpelación. Granada: Atrio. 
Suñén, Juan Carlos (1994): “¿Crítica militante? Problemas de la poesía al filo del milenio". En: Diablotexto, 1, pp. 13-27.

Villena, Luis Antonio de (ed.) (1997): 10 menos 30. La ruptura interior en la "poesía de la experiencia". Valencia: Pre-Textos.

— (ed.) (1992): Fin de siglo. El sesgo clásico en la última poesía española. Madrid: Visor.

— (ed.) (1986): Postnovísimos. Madrid: Visor.

YAnke, Germán (ed.) (1996): Los poetas tranquilos. Antología de la poesía realista del fin de siglo. Granada: Diputación Provincial (Maillot Amarillo). 